\title{
Relations Between Photosynthetic Parameters and Drought-Induced Tuber Yield Decrease in Katahdin-Derived Potato Cultivars
}

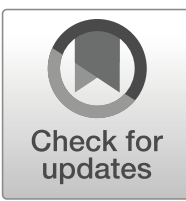

\section{Jarosław Plich ${ }^{1}$ (D) Dominika Boguszewska-Mańkowska ${ }^{2}$ (D) Waldemar Marczewski ${ }^{1}$}

Received: 30 September 2019 / Accepted: 10 January 2020 /

Published online: 12 February 2020

(C) The Author(s) 2020

\begin{abstract}
Potato (Solanum tuberosum L.) is considered a drought-sensitive crop species, although cultivar-dependent differences in tolerance have been described. The extent of droughtinduced tuber yield decreases is considered the main criterion for potato tolerance to drought. In this study, eighteen closely related potato cultivars were subjected to drought stress, and among them, two groups with contrasting drought tolerance phenotypes were distinguished (tolerant: Sebago, Katahdin and Cayuga; susceptible: Sequoia and Carpatin). Photosynthesis is the most important primary metabolic process that determines the yield of potato crops and is also strongly affected by drought. The photosynthetic parameters of these two groups of potato cultivars were assessed by measuring chlorophyll $a$ fluorescence. Drought-induced changes in the examined parameters were observed in both groups of cultivars, but the changes in the drought-sensitive group were relatively much more pronounced. The tolerant and sensitive groups significantly differed in terms of most photosynthetic parameters. Principal component analysis (PCA) revealed differences in the responses of the examined potato cultivars and separated tolerant cultivars from sensitive ones, similar to the criterion of the relative decrease in tuber yields. These results suggest that chlorophyll $a$ fluorescence may serve as a useful tool for estimating the level of tolerance to drought stress in potato.
\end{abstract}

Keywords Chlorophyll $a$ fluorescence JIP parameters · Potato yield decrease · Response to drought

Electronic supplementary material The online version of this article (https://doi.org/10.1007/s11540-02009451-3) contains supplementary material, which is available to authorized users.

Jarosław Plich

j.plich@ihar.edu.pl

Extended author information available on the last page of the article 


\section{Introduction}

Potato (Solanum tuberosum L.) is the third most important crop species worldwide after rice and wheat in terms of human consumption, and its global production exceeds 388 million metric tons per year (Deuvax et al. 2014, FAOSTAT 2019). Potato is considered one of the most promising crops to reduce human hunger and poverty worldwide due to its high yield potential. However, cultivated potato is susceptible to drought, and even a short water deficit results in a reduction in tuber production (Obidiegwu et al. 2015). Due to climate change, potato crops are being increasingly grown in drought-prone areas. Since climatic models predict that global warming will further escalate drought problems, a decrease in global potato yields of $26 \%$, or even $32 \%$, in the next few decades is predicted (Hijmans 2003; Raymundo et al. 2018). In the face of climate change, there is a need to identify potato cultivars that are more adapted to drought conditions and to recognise the bases of tolerance mechanisms.

The response of potato to drought varies among cultivars. Some relatively drought-tolerant potato cultivars can produce reasonable yields even under conditions where grain crops fail (Iwama and Yamaguchi 2006). The ability of potato plants to maintain a reasonable yield of tubers under drought stress conditions is vital in agronomic and biological contexts since tubers are essential organs in the survival strategy of potato plants (Watkinson et al. 2008; Boguszewska et al. 2010). Drought-tolerant cultivars employ multiple strategies to survive under water-limited conditions and produce tubers (Shi et al. 2015; BoguszewskaMańkowska et al. 2018).

One of the most important primary metabolic processes that determines potato crop production, which is also strongly affected by drought, is photosynthesis (Germ 2008). Analysis of chlorophyll fluorescence parameters is considered an important approach for the evaluation of the health and integrity of the internal apparatus during photosynthetic processes within a leaf while providing a platform for the rapid and precise detection and quantification of plant tolerance to drought stress (Vertucci et al. 1985; Chaerle and van der Straeten 2000; Clavel et al. 2006; Buerling et al. 2013). The JIP test (a test analyzing fast chlorophyll fluorescence kinetics) allows the measurement of several photosynthetic parameters (Strasser et al. 1995). These parameters might estimate the influence of stress on growth and yield because these traits are closely correlated with the rate of carbon dioxide exchange (Fracheboud et al. 2004; Czyczyło-Mysza et al. 2011). Moreover, these parameters serve as reliable indicators to evaluate the energetic and metabolic imbalance of photosynthesis and yield performance across genotypes under limited water/stress scenarios (Araus et al. 1998).

In our recent paper concerning the influence of drought stress on potato, we reported differences in the relative water content and drought-induced yield decreases among eighteen cultivars from the half-sib family of Katahdin-derived potato cultivars (Sołtys-Kalina et al. 2016). Here, we present results of the drought-induced yield decreases in these cultivars during a 3-year experiment. In addition, differences in photosynthetic parameters between the selected droughttolerant and drought-sensitive potato cultivars are reported. 


\section{Materials and Methods}

\section{Plant Material}

The experiments were carried out on 18 potato cultivars comprising cultivar Katahdin and seventeen potato cultivars with Katahdin as a parent. All the cultivars were obtained from the potato collection at the Plant Breeding and Acclimatization Institute - National Research Institute, Bonin, Poland. The examined cultivars represent all maturity classes: first-early (Dalila, Humalda), early (Igor, Urgenta), mid-early (Ari, Carpatin, Cayuga, Ermak, Magura, Pontiac, Sebago and Ympa) and late (Calrose, Katahdin, Seneca, Sequoia, Ulster Supreme and Wauseon).

\section{Evaluation of Potato Tuber Yield}

Experiments were conducted in three consecutive years during 2015-2017 according to methods described by Sołtys-Kalina and co-workers (Sołtys-Kalina et al. 2016). During each year, twenty-five cut tuber pieces of each cultivar were planted into pots and maintained under greenhouse conditions for 4 weeks. After this period, eighteen plants of equal height of each cultivar were transferred to tents in which the ground was lined with foil to prevent water soaking. The plants were planted in cylindrical plastic bags $(26 \mathrm{~cm}$ in height, $\sim 25 \mathrm{~cm}$ in diameter) filled with soil. To ensure the same amount of water was applied to each plant, a capillary watering system was applied. In the experiment, two treatments were performed: drought stress and watered control. For each treatment, a randomised complete block design was applied, with three blocks (replications) and three plants per block. In total, 18 plants of each cultivar ( 2 treatments, 3 blocks per treatment and 3 plants per block) were tested in the experiment. For the first 4 weeks of the experiment, all plants in both treatments were watered equally. Afterwards, half of the tested plants (drought stress treatment) were completely devoid of watering for the next 3 weeks, while the second half (control treatment) was still irrigated optimally. After this period, again, both treatments were irrigated equally until the pronounced symptoms of natural dying of the plant foliage occurred. The tubers produced by each plant were harvested and weighed individually. For each replication, the mean values of tuber yield per plant were calculated.

\section{Measurements of Chlorophyll $a$ Fluorescence}

Measurements of the kinetics of chlorophyll $a$ fluorescence were performed in two vegetation periods (2016 and 2017) using five selected cultivars with contrasting phenotypes in terms of their drought tolerance level (drought tolerant: Sebago, Katahdin and Cayuga; drought sensitive: Carpatin and Sequoia). The measurements were performed twice a year: after 20 days of drought treatment (term I drought) and at 3 days after drought release (term II - recovery). Each time, nine measurements per cultivar per treatment were performed (three technical repetitions for each three biological replications). The kinetics of chlorophyll $a$ 
fluorescence were measured in the middle region of fully expanded and third- and fourth-level mature apical leaves of potato plants using a multifunctional plant efficiency analyser (Handy-PEA fluorimeter, Hansatech Instruments Ltd., Pentney, King's Lynn, Norfolk, England) and Pea Plus software. Before measuring, the plants were dark adapted for at least 30 min between 9:00 and 11:00 am (local solar time). Leaf clips were applied to fully sun-exposed leaflets. The measurements were made with saturation irradiance up to $3000 \mu \mathrm{mol} \mathrm{m} \mathrm{m}^{-2} \mathrm{~s}^{-1}$. For analysis, nineteen JIP parameters were chosen (a description of parameters, along with the references to publications describing these parameters, is given in Table 1).

Table 1 Selected JIP-test parameters calculated on the basis of fast fluorescence kinetics

\begin{tabular}{|c|c|c|}
\hline $\begin{array}{l}\text { Fluorescence } \\
\text { parameters }\end{array}$ & Description & References \\
\hline $\mathrm{T}_{\mathrm{FM}}$ & $\begin{array}{l}\text { Time }(\mathrm{ms}) \text { to reach } \\
\text { maximum fluorescence level }\left(\mathrm{F}_{\mathrm{M}}\right)\end{array}$ & 1 \\
\hline Area & Area above the OJIP curve between Fo and Fm and the Fm & 2 \\
\hline Fo & $\begin{array}{l}\text { Minimum fluorescence, when all PSII reaction centres (RCs) are open, } \\
\text { fluorescence intensity at } 20 \mu \mathrm{s}\end{array}$ & $1,2,3$ \\
\hline $\mathrm{Fm}$ & $\begin{array}{l}\text { Maximum fluorescence measured after a saturating pulse in light- and } \\
\text { dark-adapted samples }\end{array}$ & $1,2,3$ \\
\hline Fv & Maximal variable fluorescence, $\mathrm{F}_{\mathrm{V}}=\mathrm{F}_{\mathrm{M}}-\mathrm{F}_{0}$ & 1 \\
\hline $\mathrm{Fv} / \mathrm{Fm}$ & The maximum quantum yield of PSII photochemistry & 1,2 \\
\hline $\mathrm{Fv} / \mathrm{Fo}$ & $\begin{array}{l}\text { The parameter in proportion to the ratio of reactions of photochemical and } \\
\text { non-photochemical energy quenching in PSII reaction centre. It is also } \\
\text { linked with efficiency of the water-splitting complex on the donor side of } \\
\text { PSII }\end{array}$ & 1,2 \\
\hline$\Delta \mathrm{VG} / \Delta$ to & The initial slope of chlorophyll fluorescence rise & 1 \\
\hline$\Delta \mathrm{V} / \Delta$ to & Express the speed of closing reaction centres of PSII & 1 \\
\hline $\mathrm{N}$ & $\begin{array}{l}\text { The number indicating how many times } Q_{A} \text { is reduced while the fluorescence } \\
\text { reaches its maximal value } F_{M} \text { (number of } Q_{A} \text { redox turnovers until Fm is } \\
\text { reached) }\end{array}$ & 1 \\
\hline $\mathrm{ABS} / \mathrm{RC}$ & Absorbed energy flux in antenna Chls per PSII reaction centre & 1,2 \\
\hline $\mathrm{Dlo} / \mathrm{RC}$ & Energy dissipation flux per RC & 2 \\
\hline Tro/RC & Trapping flux leading to $\mathrm{Q}_{\mathrm{A}}$ reduction per $\mathrm{RC}$ & 2 \\
\hline Eto/RC & Electron transport flux per $\mathrm{RC}$ at $t=0$ & 1,2 \\
\hline $\mathrm{Reo} / \mathrm{RC}$ & $\begin{array}{l}\text { Electron flux reducing end electron acceptors at the PSI acceptor side, per } \\
\text { RC }\end{array}$ & 1,3 \\
\hline Dlo/Cso & Dissipated energy flux per CS at $t=0$ & 1,3 \\
\hline $\mathrm{PI}_{\mathrm{ABS}}$ & Performance index of PSII based to absorption & 1,2 \\
\hline $\mathrm{dRo} /(1-\mathrm{dRo})$ & Contribution of PSI, reducing its end acceptors & 3 \\
\hline $\mathrm{PI}_{\mathrm{TOTAL}}$ & $\begin{array}{l}\text { Performance index: the performance of electron flux to the final PSI electron } \\
\text { acceptors }\end{array}$ & 1,2 \\
\hline
\end{tabular}

\footnotetext{
a 1 (Samborska et al. 2019); 2 (Kalaji et al. 2018); 3 (Duarte et al. 2016)
}

$R C$, reaction centre; $Q_{A}$, bound plastoquinone particles; $C S$ cross-section 


\section{Statistical Analyses}

Yield Analysis To assess the influence of year, treatment and cultivar on tuber yield, three-way and two-way ANOVAs were applied. For each cultivar, planned comparisons (based on two-way ANOVAs performed for each year separately) between the tuber yields of plants subjected to drought stress and plants from the control treatment were calculated. For each tested cultivar, the relative decrease in tuber yield after water shortage was also calculated according to the following formula: $100 \times[$ (mean value of tuber yield per plant from the control treatment - mean value of tuber yield per plant from the soil drought treatment)/(mean value of tuber yield per plant from the control treatment)]. Pearson's correlation coefficient $(r)$ values between the relative yield decreases in each year of the experiment were also calculated.

Analysis of Chlorophyll $a$ Fluorescence Parameters To assess the influence of the group of cultivars (tolerant vs sensitive), treatment (plants subjected to drought stress vs the control) and year of the experiment on the fluorescence parameters, three-way ANOVAs were applied (separately for term I (drought) and term II (recovery)). Direct comparisons of the values of particular parameters between treatments (stressed and control) were also performed, and results were presented as spider plots (radar charts). To perform these comparisons, the mean values of particular parameters for each group of cultivars (tolerant and sensitive) from the control treatment and from the stressed treatment were calculated, and the relation percentage between these two values was calculated. Based on the mean values of particular parameters for each cultivar from each treatment and term, PCA (principal component analysis) was also performed.

All statistical analyses were performed with the use of MS Excel and STATISTICA 12.

\section{Results}

Yield Analysis According to the three-way ANOVA, the factors "cultivar," "year," and "treatment," as well as interaction between these factors, significantly influenced tuber yield in our experiment (for the factors "cultivar," "year," and "treatment" as well as the "cultivar $\times$ treatment" interaction, $P<0.001$; for the "cultivar $\times$ year," and "treatment $\times$ year" interactions, $P<0.01)$. Only the influence of the "cultivar $\times$ treatment $\times$ year" interaction on tuber yield was statistically insignificant $(P=0.156)$. Water deficit significantly affected tuber yield. Plants of all examined cultivars subjected to drought stress yielded less than plants from the control treatment (the only exception was the result for cultivar Cayuga in 2016 (Table 2). However, the strength of the reactions of the potato plants under drought stress differed among cultivars and years. The 3 -year means of the relative yield decrease caused by the drought treatment varied between $13.2 \%$ and $57.3 \%$, while the results for separate years ranged from -1.0 to $73.0 \%$ (Table 2). The values of the yield decreases of the examined cultivars in all 3 years of experiments were significantly correlated $(r=0.69$ for 2015 and 2016, $r=0.55$ for 2015 and 2017, $r=0.39$ for 2016 and 2017). 
Table 2 Relative yield decrease (percentages) of examined potato cultivars in years 2015-2017

\begin{tabular}{lllll}
\hline Cultivar & \multicolumn{2}{l}{ Relative yield decrease } & & \\
\cline { 2 - 5 } & 2015 & 2016 & 2017 & mean \\
\hline Sebago & 26.4 & $10.0^{\mathrm{ns}}$ & $3.1^{\mathrm{ns}}$ & 13.2 \\
Katahdin & 19.4 & 22.8 & 15.8 \\
Cayuga & 21.4 & $-1.0^{\mathrm{ns}}$ & 32.1 & 17.8 \\
Ulster Supreme & 21.9 & $13.4^{\mathrm{ns}}$ & 23.0 & 19.5 \\
Ari & 30.4 & $11.5^{\mathrm{ns}}$ & 32.5 & 24.8 \\
Pontiac & 27.4 & 20.6 & 29.6 & 25.9 \\
Magura & $19.0 \mathrm{~ns}$ & 32.9 & 26.6 & 26.2 \\
Urgenta & 32.1 & $11.4^{\mathrm{ns}}$ & 40.4 & 28.0 \\
Wauseon & 30.5 & 30.1 & 27.8 & 29.4 \\
Seneca & 37.6 & $18.8^{\mathrm{ns}}$ & 33.3 & 29.9 \\
Humalda & $5.0^{\mathrm{ns}}$ & 55.5 & 30.1 \\
Calrose & 30.0 & 25.2 & 24.7 & 30.7 \\
Ympa & 42.2 & 25.9 & 46.9 & 31.6 \\
Dalila & 22.0 & 28.6 & 27.8 & 32.6 \\
Ermak & 41.3 & 34.3 & 36.6 & 35.3 \\
Igor & 35.2 & 35.0 & 26.2 & 38.2 \\
Sequoia & 53.5 & 43.0 & 67.3 & 57.1 \\
Carpatin & 60.9 & 40.1 & 73.0 & 57.3 \\
\hline
\end{tabular}

${ }^{\text {ns }}$ Not significant—lack of statistically significant differences between tuber yield from control and stressed treatment (according to planned comparisons)

Planned comparisons showed that in most cases, the differences in yield between plants subjected to drought stress treatment and plants from the control treatment were statistically significant. However, each year, there were cultivars whose differences in tuber yields in both treatments were statistically insignificant: one cultivar in 2015, eight cultivars in 2016 and one cultivar in 2017 (Table 2).

Based on the 3-year mean values of the relative decreases in tuber yield, two groups of cultivars with contrasting phenotypes were separated: the most drought tolerant (Sebago, Katahdin and Cayuga) and the most drought sensitive (Carpatin and Sequoia) (Table 2).

Chlorophyll $a$ Fluorescence Analysis The three-way ANOVAs showed that the group of cultivars, treatment and year factors significantly influenced the values of JIP parameters (Supplementary Table 1, Online Resource 1). The groups of droughttolerant and drought-sensitive potato cultivars significantly differed in terms of most JIP parameters measured during drought stress (term I) and after recovery (term II). The results of the measurements performed in term I (20 days of drought) showed statistically significant differences between the tolerant and sensitive cultivars among fourteen of nineteen tested JIP parameters (Area, Fo, $\mathrm{Fv} / \mathrm{Fm}, \mathrm{Fv} / \mathrm{Fo}, \Delta \mathrm{VG} / \Delta$ to, $\Delta \mathrm{V} / \Delta$ to, $\mathrm{ABS} / \mathrm{RC}, \mathrm{Dlo} / \mathrm{RC}, \mathrm{Tro} / \mathrm{RC}, \mathrm{Eto} / \mathrm{RC}, \mathrm{Dlo} / \mathrm{Cso}$, 
$\mathrm{PI}_{\mathrm{ABS}}$, Dro/(1-dRo) and $\left.\mathrm{PI}_{\mathrm{TOTAL}}\right)$. The measurements performed in term II (3 days after recovery) significantly differed in terms of the same JIP parameters (except Fo) and in terms of the Fm, Fv, N and Reo/RC parameters (Supplementary Table 1, Online Resource 1).

When the mean values of the JIP parameters from term I (drought) for tolerant and sensitive cultivars were compared to their values from the control treatments, differences between these groups of cultivars were observed (Fig. 1a). The values of parameter $T_{\mathrm{FM}}$ were higher in the stressed plants than in the control plants, but differences between the groups of cultivars (sensitive and tolerant) were statistically insignificant. The values of the area above the OJIP curve between Fo and Fm (the parameter area) decreased only by $3 \%$ in the drought-tolerant potato cultivars and by $25 \%$ in the drought-sensitive potato cultivars (Fig. 1a, Supplementary Table 1, Online Resource 1). According to the speed of energy flux, the minimum fluorescence value when all PSII RCs are open (Fo) increased more in the drought-sensitive cultivars than in the drought-tolerant cultivars $(112 \%$ and $106 \%$, respectively). A slightly higher increase in the parameters Fm and Fv was observed for the sensitive than for the tolerant cultivars, but the differences were statistically insignificant. The parameters associated with the quantum yield and efficiency, maximum quantum efficiency of PSII photochemistry (Fv/Fm) and efficiency of the water-splitting complex on the donor side of PSII (Fv/Fo) decreased more in the drought-sensitive cultivars than in the drought-tolerant cultivars. Additionally, the initial slope of the chlorophyll fluorescence increase $(\Delta \mathrm{VG} / \Delta$ to $)$ and the speed of the closing reaction centres of PSII $(\Delta \mathrm{V} / \Delta$ to $)$ increased much more in the drought-sensitive cultivars than in the drought-tolerant cultivars $(173 \%$ and $162 \%$, respectively, in the sensitive cultivars and $114 \%$ and $112 \%$, respectively, in the tolerant cultivars). In the case of parameter $N$, the mean values of the sensitive cultivars decreased, while they increased in the tolerant cultivars (the differences were statistically insignificant). Significant differences between the sensitive and tolerant cultivars induced by drought were also noted for the parameters $\mathrm{ABS} / \mathrm{RC}(142 \%$ and $117 \%$, respectively), Dlo/RC (142\% and $117 \%$, respectively) and Tro/RC (133\% and $110 \%$, respectively). In the case of the Eto/RC parameter, a slight decrease was observed in the sensitive cultivars $(99 \%$ of control), and an increase in the tolerant cultivars was observed (108\% of control). Differences between the examined groups of cultivars were also observed in terms of changes in the parameters Dlo/Cso and dRo/(1-dRo) $(94 \%$ vs $106 \%$ and $121 \%$ vs $112 \%$ of control for the sensitive and resistant cultivars, respectively). When we compared the results of the $\mathrm{PI}_{\mathrm{ABS}}$ and $\mathrm{PI}_{\mathrm{TOTAL}}$ measurements from the drought stress treatment to the results from the control conditions, significant decreases in these parameters were observed in both groups of cultivars. However, in the drought-tolerant potato cultivars, the decreases were $15 \%$ and $13 \%$, respectively, for the $\mathrm{PI}_{\mathrm{ABS}}$ and the $\mathrm{PI}_{\mathrm{TOTAL}}$, while in the drought-sensitive cultivars, the decreases were much greater and equalled $47 \%$ and $54 \%$, respectively.

In the case of measurements performed in term II (3 days of recovery period), differences between the tolerant and sensitive cultivars were also observed (Fig. 1b, Supplementary Table 1, Online Resource 1). Unlike term I (drought), in term II (recovery) measurements performed 3 days after re-watering, the values of the parameter $\mathrm{T}_{\mathrm{FM}}$ were lower in the stressed plants than in the control plants, and 

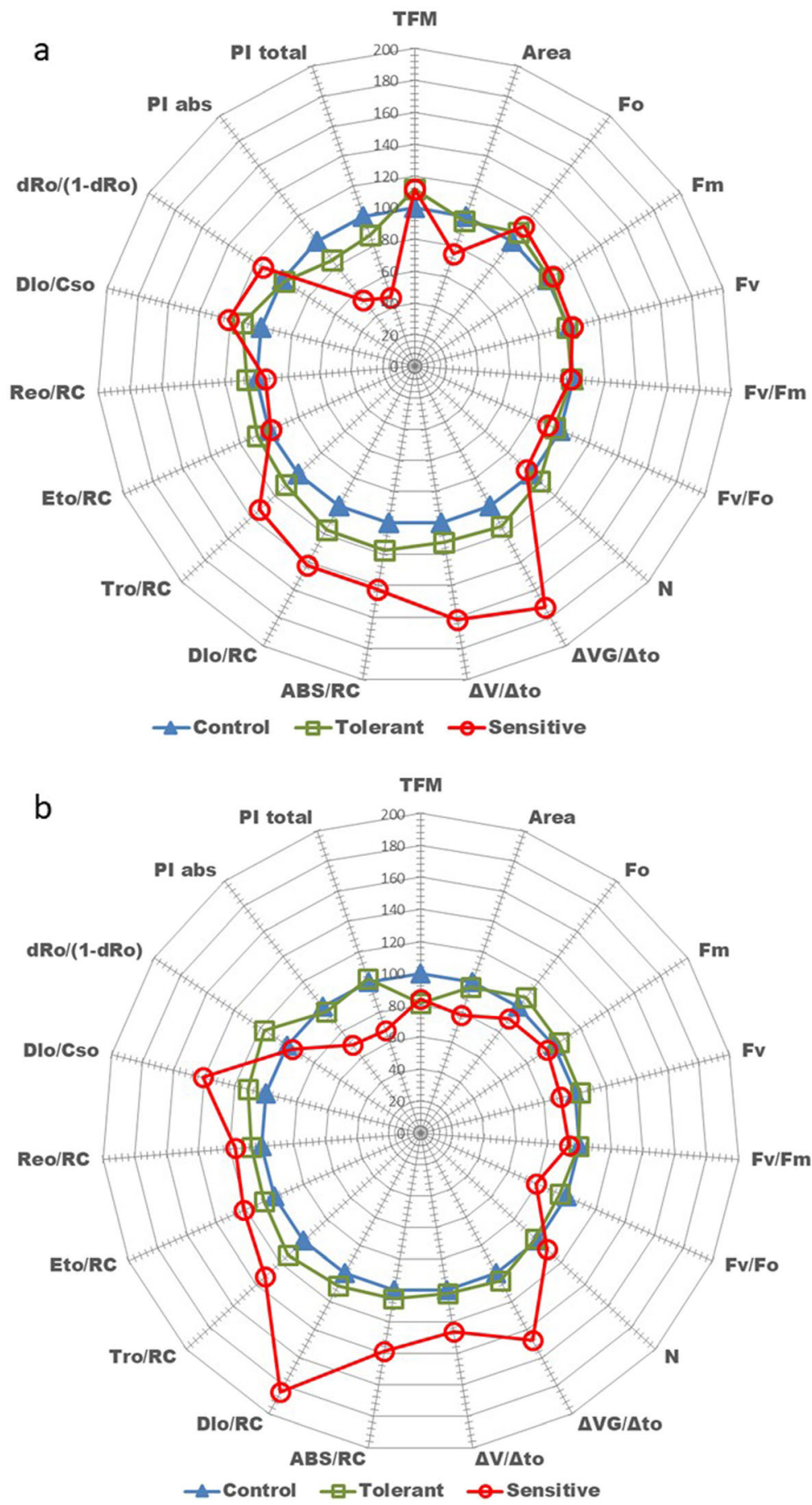

differences between the groups of cultivars (sensitive and tolerant) were statistically insignificant. The levels of drought-induced changes in the parameter area 
Fig. 1 A "spider plot" of selected JIP test parameters. Mean values (shown as the percentages of the corresponding values of the control) of drought-tolerant and drought-sensitive potato cultivars measured in a term I (20 days of drought) and b term II (3 days after drought release). Tolerant-group of three droughttolerant potato cultivars (Sebago, Katahdin and Cayuga), Sensitive-group of drought-sensitive potato cultivars (Carpatin and Sequoia), Control-mean value of each group of potato cultivars from the control treatment, expressed as $100 \%$. $\mathrm{T}_{\mathrm{FM}}$ - time at which the maximum fluorescence value (Fm) was reached, Area - area above the OJIP curve between Fo and Fm, Fo - minimum fluorescence, when all PSII RCs are open, Fm - maximum fluorescence, Fv - maximum variable fluorescence, Fv/Fm — maximum quantum efficiency of PSII photochemistry, Fv/Fo - efficiency of the water-splitting complex on the donor side of PSII, $\Delta \mathrm{VG} / \Delta$ to - initial slope of the chlorophyll fluorescence rise, $\Delta \mathrm{V} / \Delta$ to - speed of the closing reaction centres of PSII, N-the number indicating how many times QA is reduced while the fluorescence reaches its maximal value, $\mathrm{ABS} / \mathrm{RC}$ - absorption flux per $\mathrm{RC}, \mathrm{Dlo} / \mathrm{RC}$ - dissipated energy flux per $\mathrm{RC}$, Tro/RC - trapping flux leading to $\mathrm{QA}$ reduction per $\mathrm{RC}, \mathrm{Eto} / \mathrm{RC}$ - electron flux per $\mathrm{RC}$ at $t=0, \mathrm{Reo} / \mathrm{RC}$ - electron flux reducing the terminal electron acceptors at the PSI acceptor side per RC, Dlo/Cso - dissipated energy flux per cross-section (CS) at $t=0, \mathrm{PI}_{\mathrm{ABS}}$ - performance index of PSII based on absorption, $\mathrm{dRo} /(1-\mathrm{dRo})$ - contribution of PSI to reducing the terminal acceptors, $\mathrm{PI}_{\mathrm{TOTAL}}$ - performance index: the performance of electron flux to the final PSI electron acceptors

were similar to those in term I (78\% and $96 \%$ of the control for the sensitive and tolerant cultivars, respectively). The level of parameter Fo in the drought-tolerant cultivars ( $108 \%$ of control) was similar to that in term I but was much lower in the case of sensitive cultivars (90\% of control). However, the differences between groups of cultivars were statistically insignificant. Changes in the parameters Fm, $\mathrm{Fv}$ and $\mathrm{Fv} / \mathrm{Fm}$ were not large, but in the case of the sensitive cultivars, the values of these parameters were lower compared with the control. The parameter Fv/Fo in the group of tolerant cultivars remained at the same level as that in term I, while in the sensitive cultivars, this parameter greatly decreased and equalled $79 \%$ of the control. Unlike in term I, the parameter $N$ slightly decreased in the tolerant cultivars but increased in the sensitive cultivars. The parameters $\Delta \mathrm{VG} / \Delta$ to, $\Delta \mathrm{V} /$ $\Delta$ to, $\mathrm{ABS} / \mathrm{RC}, \mathrm{Dlo} / \mathrm{RC}, \mathrm{Tro} / \mathrm{RC}, \mathrm{Eto} / \mathrm{RC} \mathrm{Reo} / \mathrm{RC}$ and $\mathrm{Dlo} / \mathrm{Cso}$ were slightly elevated in the tolerant cultivar group and were greatly elevated in the sensitive cultivars. The parameter $\mathrm{dRo} /(1-\mathrm{dRo})$, unlike in term I, slightly decreased in the sensitive cultivars but increased in the tolerant ones. In the case of the $\mathrm{PI}_{\mathrm{ABS}}$ and $\mathrm{PI}_{\mathrm{TOTAL}}$ parameters, their values for the tolerant cultivars were similar to those of the control but remained decreased in the sensitive cultivars $(70 \%$ and $68 \%$ of control, respectively).

Principal component analysis (PCA) of the fluorescence parameters of the examined potato cultivars revealed both differences and similarities between these potato cultivars. The total variability among genotypes for the nineteen selected OJIP parameters was efficiently summarised by the first and second principal components (PC1 and PC2). Under different control (C) and drought (D) conditions, PC1 explained $58.57 \%$ of the total variability, whereas PC2 explained $39.87 \%$ of the total variability. Under different control (C) and drought treatments in term II (recovery R), PC1 explained $80.59 \%$ of the total variability, whereas PC2 explained $14.13 \%$. In the case of both terms (drought and recovery), the PCA separated tolerant potato cultivars from sensitive ones, similar to the criterion of the relative decrease in tuber yield. The tolerant potato cultivars under the control and drought conditions were placed close to each other in the same quarter of the chart, while the sensitive cultivars were more dispersed (Fig. 2a, b). 

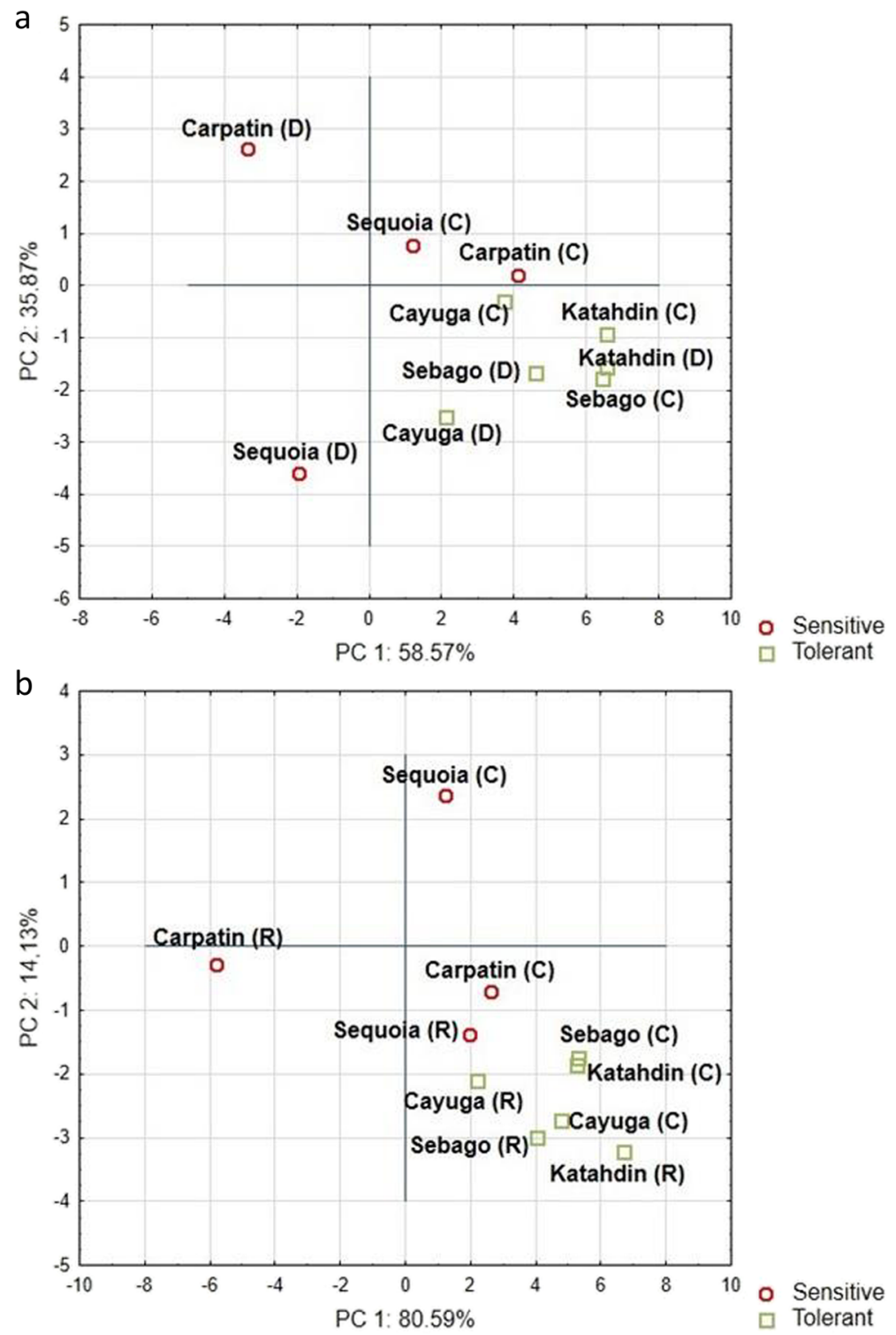

Fig. 2 Biplot of the results of a principal component analysis (PCA) of five examined potato cultivars (three tolerant ones, Sebago, Katahdin and Cayuga, and two susceptible ones, Sequoia and Carpatin) based on analyses of the mean values of nineteen JIP test parameters in a term I (20 days of drought stress) and $\mathbf{b}$ term II (3 days after drought release). $\mathrm{D}$ — drought treatment; $\mathrm{R}$ - recovery treatment; $\mathrm{C}$ - control treatment

\section{Discussion}

Potato is a drought-sensitive crop species, and water deficiency greatly influences the growth and yield of potato. However, genotype-dependent differences in yield maintenance under water stress have been reported (Lahlou et al. 2003; Schafleitner et al. 2007; Sołtys-Kalina et al. 2016; Boguszewska-Mańkowska et al. 2018). Our 3-year 
study clearly showed that strong diversification in drought tolerance levels is present even in genetically closely related potato cultivars. In all tested cultivars, a droughtinduced yield decrease was observed, but the level depended on the cultivar and year of the experiment. In some cases (Table 2), differences between tuber yields from droughtstressed and control treatments were small and statistically insignificant. The 3-year mean values of the relative yield decrease varied between $13.2 \%$ and $57.3 \%$. Based on these values, the most tolerant (Sebago, Katahdin and Cayuga) and the most sensitive (Carpatin and Sequoia) potato cultivars were selected. As in our previous study (SoltysKalina et al. 2016), Sequoia and Carpatin presented the highest relative yield decrease (more than $71 \%$ and $63 \%$, respectively). The levels of the relative yield decreases of the remaining cultivars in the previous and present study were also similar (differences up to $16 \%$ ). Only for cultivar Ari did the mean relative yield decrease equal to $25 \%$ in the present study and $53 \%$ in the previous study (Sołtys-Kalina et al. 2016). Pearson's correlation coefficient $(r)$ between the mean values of the relative yield decrease in both studies is 0.74 .

It is well known that photosynthetic activity is reduced when plants are exposed to environmental stress (Retuerto et al. 2006; Prinzenberg et al. 2018). Drought stress reduces plant growth by reducing photosynthesis, which is mainly caused by stomatal limitation. Decreases in stomatal conductance reduce water loss through transpiration, but it also decreases carbon dioxide uptake, reducing the production of photoassimilates and plant growth. With severe water stress, in addition to the stomatal limitation of photosynthesis, the presence of non-stomatal limitations related to damage to the photosynthetic apparatus has been reported (Rodriguez-Perez et al. 2017). Chlorophyll fluorescence dynamics parameters constitute the ideal method to study and measure the influence of drought stress on the photosynthesis of plants in a rapid, sensitive and non-invasive way (Banks 2018; Boguszewska-Mańkowska et al. 2018). Analysis using the JIP test parameters allows us to assess the impact of different stresses on the efficiencies and fluxes of electrons and of the energy around PSI and PSII (Maxwell and Johanson 2000). Chlorophyll fluorescence measurements can be used for comparison of photosynthetic electron transport between cultivars with contrasting drought tolerance phenotypes and for the selection of drought-tolerant cultivars ( $\mathrm{Li}$ and Liu 2016). We used photosynthetic parameters to compare the response to drought between two groups of potato cultivars with contrasting phenotypes: droughttolerant (with a low relative yield decrease) and drought-susceptible (with the highest relative yield decrease) phenotypes. Drought-induced changes in JIP parameters were observed in both groups of cultivars, but the changes in the group of sensitive cultivars were much more pronounced. In the case of drought-sensitive cultivars subjected to 20 days of drought stress, the most pronounced differences were observed in the levels of the parameters $\Delta \mathrm{VG} / \Delta$ to,$\Delta \mathrm{V} / \Delta$ to, $\mathrm{ABS} / \mathrm{RC}, \mathrm{Dlo} / \mathrm{RC}$, Tro/RC and Dlo/Cso (increased levels), as well as the area, $\mathrm{PI}_{\mathrm{ABS}}$ and $\mathrm{PI}_{\mathrm{TOTAL}}$ parameters (decreased values). The same type of reaction (increase or decrease) that occurred in the sensitive cultivars was also observed in the tolerant cultivars, but the extent of changes in comparison to the control treatment was much lower (Fig. 1a). A similar situation was also observed even 3 days after drought release (term II), and much greater changes in the examined parameters were observed in the drought-sensitive group compared with the tolerant cultivar group. The most pronounced differences between the stressed and control treatment in the sensitive cultivars were observed for Fv/Fo, $\Delta \mathrm{VG} / \Delta$ to, $\Delta \mathrm{V} / \Delta$ to, ABS/ 
$\mathrm{RC}, \mathrm{Dlo} / \mathrm{RC}, \mathrm{Tro} / \mathrm{RC}, \mathrm{Eto} / \mathrm{RC}, \mathrm{Reo} / \mathrm{RC}$ and $\mathrm{Dlo} / \mathrm{Cso}$ (increased levels), as well as for area, $\mathrm{PI}_{\mathrm{ABS}}$ and $\mathrm{PI}_{\mathrm{TOTAL}}$ (decreased values). Boguszewska-Mańkowska et al. (2018) observed a large increase in the parameters $\mathrm{ABS} / \mathrm{RC}, \mathrm{Dlo} / \mathrm{RC}$ and $\mathrm{Tro} / \mathrm{RC}$ and a large decrease in $\mathrm{PI}_{\mathrm{ABS}}$ in drought-susceptible potato cultivars subjected to drought, and in the parameters $\mathrm{ABS} / \mathrm{RC}, \mathrm{Tro} / \mathrm{RC}$ and especially Dlo/RC (increase) and the $\mathrm{PI}_{\mathrm{ABS}}$ (decrease) after drought stress release. Li and coworkers (Li et al. 2006) observed variability in Fo, Fv, Fm and Fv/Fm between barley cultivars, and the ratio of these parameters decreased under drought conditions, but the decrease was more pronounced for the sensitive cultivar than for the tolerant one.

Performance indices (the $\mathrm{PI}_{\mathrm{ABS}}$ and the $\mathrm{PI}_{\mathrm{TOTAL}}$ ) are used to express the energy bifurcation in PSII. These indices indicate the general physiological state of PSII in a sample. When we compared the results of the $\mathrm{PI}_{\mathrm{ABS}}$ and $\mathrm{PI}_{\mathrm{TOTAL}}$ measurements from term I (drought) from the drought stress treatment to the results from the control conditions, a decrease in these parameters was observed in both groups of cultivars. However, in the drought-tolerant potato cultivars, the levels of these parameters were reduced by approximately $13-15 \%$, while the sensitive cultivars showed a reduction of approximately $50 \%$. In the case of measurements performed in term II (recovery) in the drought-tolerant cultivars from the stressed treatment, both parameters were at levels similar to those in the control treatment $\left(\mathrm{PI}_{\mathrm{ABS}}-96 \%\right.$ of the control; $\mathrm{PI}_{\mathrm{TOTAL}}-102 \%$ of the control). In the group of drought-sensitive cultivars, the mean values of both of these parameters were still approximately $30 \%$ lower in the stressed treatment than in the control.

Similar results were obtained in winter wheat, where the PI under irrigation conditions was greater than that under drought stress, and in high-yielding lines, the PI was greater than that in low-yielding genotypes. The relatively low $\mathrm{PI}_{\mathrm{ABS}}$ and $\mathrm{PI}_{\mathrm{TOTAL}}$ values were mainly due to a higher trapping flux, which led to reductions in QA per reaction centre (Tro/RC) and absorption flux per RC (ABS/RC). Higher values of ABS/ $\mathrm{RC}$ and $\mathrm{Tro} / \mathrm{RC}$, which were statistically significant, were reported for droughtsensitive cultivars than for drought-tolerant cultivars of winter wheat (Roostaei et al. 2011). In Tilia cordata Mill., 20-day-long drought stress increased the tested parameter $\mathrm{DIo} / \mathrm{RC}$ (Kalaji et al. 2018). Moreover, Wang et al. (2019) observed a large increase in the parameters $\Delta \mathrm{VG} / \Delta$ to, $\Delta \mathrm{V} / \Delta$ to, $\mathrm{ABS} / \mathrm{RC}, \mathrm{Tro} / \mathrm{RC}$ and $\mathrm{Dlo} / \mathrm{RC}$ and a large decrease in the $\mathrm{PI}_{\mathrm{ABS}}$ and $\mathrm{PI}_{\mathrm{TOTAL}}$ in lettuce (Lactuca sativa $\mathrm{L}$.) plants as a result of cadmium (Cd) stress treatment.

In the drought-tolerant cultivars, the $\mathrm{DIo} / \mathrm{RC}$ parameter was only $9 \%$ higher than that under control conditions whereas in the drought-sensitive cultivars, it was $185 \%$ of the control (Fig. 1b). An increase in DIo/RC could be linked to the inactivation of reaction centres, which would cause them to become heat sinks as described by Franic et al. (2017) in the case of maize.

Considering phenomenological energy fluxes per excited cross-section (CS), the dissipated energy flux per cross-section (CS) parameter at $t=0$ (Dlo/Cso) significantly increased $9 \%$ more in the drought-sensitive potato cultivars than in the tolerant potato cultivars. Higher values of DIo/Cs indicate low energy trapping efficiency in the PSII reaction centre (Rapacz et al. 2019).

PCA ordination provided an overall picture of the fluorescence parameters of the examined potato cultivars and revealed both differences and similarities in the responses of potato groups that differed in drought tolerance. The total variability among 
genotypes for photosynthetic parameters was efficiently summarised by PC1 and PC2, which explained in total more than $90 \%$ of the total variability observed in the 20th day of drought stress as well as after 3 days of re-watering. PCA separated the examined potato cultivars similar to the criterion of the relative decrease in tuber yield under drought conditions (term I) and after re-watering (term II). The tolerant potato cultivars in the control and drought conditions were placed close to each other in the same quadrant of the chart, while the sensitive cultivars were more dispersed (Fig. 2a, b).

Although Mescht and coworkers (Van der Mescht et al. 1999) concluded that chlorophyll fluorescence can be used as a measure of drought tolerance in potato cultivars only with a short growth period, our results did not confirm this conclusion because all cultivars from both the tolerant and sensitive groups are mid-early (Carpatin, Cayuga and Sebago) or late (Katahdin and Sequoia) types, and significant differences in JIP parameters between these groups were found.

In conclusion, drought stress resulted in changes in chlorophyll fluorescence parameters in both drought-tolerant and drought-sensitive potato cultivars (despite their maturity), but the level of these changes was much greater in those potato cultivars for which the drought-induced tuber yield decrease was highest. These results suggest that measurements of chlorophyll $a$ fluorescence may serve as a useful tool for estimating the level of tolerance to drought stress in potato.

These findings demonstrate the various capabilities of potato cultivars to confer acclimation to water deficit within the life of a plant. The results of our preliminary studies (data not published) indicate that the effect of prior drought stress can also be observed in the following generation of potato plants. Additional knowledge is necessary to gain insight into the molecular mechanisms of drought stress memory in potato plants and how this memory is transmitted to non-stressed progeny.

Author Contribution JP, DB-M and WM designed the experiments; JP carried out the yield experiments (with assistance from technical staff), analysed the results of the experiments, assisted in the fluorescence measurements and analysis of obtained data and wrote the manuscript; DB-M performed the fluorescence measurements, analysed the obtained data and contributed to the manuscript preparation; and WM supervised the work and revised the manuscript.

Funding Information This study was financed by statutory grant 1-3-00-3-03 from the Polish Ministry of Science and Higher Education.

\section{Compliance with Ethical Standards}

Conflict of Interest The authors declare that they have no conflict of interest.

Open Access This article is licensed under a Creative Commons Attribution 4.0 International License, which permits use, sharing, adaptation, distribution and reproduction in any medium or format, as long as you give appropriate credit to the original author(s) and the source, provide a link to the Creative Commons licence, and indicate if changes were made. The images or other third party material in this article are included in the article's Creative Commons licence, unless indicated otherwise in a credit line to the material. If material is not included in the article's Creative Commons licence and your intended use is not permitted by statutory regulation or exceeds the permitted use, you will need to obtain permission directly from the copyright holder. To view a copy of this licence, visit http://creativecommons.org/licenses/by/4.0/. 


\section{References}

Araus JL, Amaro T, Voltas J, Nakkoul H, Nachit MM (1998) Chlorophyll fluorescence as a selection criterion for grain yield in durum wheat under Mediterranean conditions. Field Crops Res 55:209-223

Banks JM (2018) Chlorophyll fluorescence as a tool to identify drought stress in Acer genotypes. Environ Exp Bot 155:118-127

Boguszewska D, Grudkowska M, Zagdańska B (2010) Drought responsive antioxidant enzymes in potato (Solanum tuberosum L.). Potato Res 53:373-382

Boguszewska-Mańkowska D, Pieczyński M, Wyrzykowska A, Kalaji HM, Sieczko L, SzweykowskaKulińska Z, Zagdańska B (2018) Divergent strategies displayed by potato (Solanum tuberosum L.) cultivars to cope with soil drought. J Agron Crop Sci 204(1):13-30

Buerling K, Cerovic ZG, Cornic G, Ducruet JM, Noga G, Hunsche M (2013) Fluorescence-based sensing of drought-induced stress in the vegetative phase of four contrasting wheat genotypes. Environ Exp Bot 89: 51-59

Chaerle L, van der Straeten D (2000) Imaging techniques and the early detection of plant stress. Trends Plant Sci 5:495-501

Clavel D, Diouf O, Khalfaoui JL, Braconnier S (2006) Genotypes variations in fluorescence parameters among closely related groundnut (Arachis hypogaea L.) lines and their potential for drought screening programs. Field Crops Res 96 (2-3):296-306

Czyczylo-Mysza I, Marcinska I, Skrzypek E, Chrupek M, Grzesiak S, Hura T (2011) Mapping QTLs for yield components and chlorophyll a fluorescence parameters in wheat under three levels of water availability. Plant Genet Resour Charact Util 9:291-295

Deuvax A, Kromann P, Ortiz O (2014) Potatoes for sustainable global food security. Potato Res 57:185-199

Duarte B, Marques J, Cacador CI (2016) Ecophysiological response of native and invasive Spartina species to extreme temperature events in Mediterranean marshes. Biol Invasions 18:2189-2205

Fracheboud Y, Jompuk C, Ribaut JM, Stamp P, Leipner J (2004) Genetic analysis of cold-tolerance of photosynthesis in maize. Plant Mol Biol 56:241-253

Franić M, Galić V, Ledenčan T, Jambrović A, Brkić I, Zdunić Z, Brkić A, Brkić J, Šimić J (2017) Changes of chlorophyll a fluorescence parameters in water limited maize IBM population. 52nd Croatian and 12th International Symposium on Agriculture. February 12-17. Dubrovnik, Croatia

Germ M (2008) The response of two potato cultivars on combined effects of selenium and drought. Acta Agric Slov 91(1):121-137

Hijmans RJ (2003) The effect of climate change on global potato production. Am J Potato Res 80:271-279

Iwama K, Yamaguchi J (2006) Abiotic stresses. In: Gopal J, Khurana SM (eds) Handbook of potato production, Improvement and Postharvest Management, NewYork, NY: Food Product Press, pp 231-278

Kalaji HM, Račková L, Paganová V, Swoczyn T, Rusinowski S, Sitko K (2018) Can chlorophyll-a fluorescence parameters be used as bio-indicators to distinguish between drought and salinity stress in Tilia cordata Mill? Environ Exp Bot 152:149-157

Lahlou O, Ouattar S, Ledent JF (2003) The effect of drought and cultivar on growth parameters, yield and yield components of potato. Agronomie 23:257-268

Maxwell K, Johanson GN (2000) Chlorophyll fluorescence - a practical guide. J Exp Bot 51:659-668

Li R, Guo P, Baumz M, Grand S, Ceccarelli S (2006) Evaluation of chlorophyll content and fluorescence parameters as indicators of drought tolerance in barley. Agr Sci China 5(10):751-757

Li X, Liu F (2016) Drought stress memory and drought stress tolerance in plants: biochemical and molecular basis. In: Hossain MA, Wani SH, Bhattacharjee S, Burritt DJ Tran L-SP (eds) Drought stress tolerance in plants, vol 1, Springer, pp 17-44

Van der Mescht FT, De Ronde A, Rossouw JA (1999) Chlorophyll fluorescence transients, decreasing intercellular $\mathrm{CO}_{2}$ concentration, drought, photosynthesis and potato production. S Afr J of Sci 95(9): $407-412$

Obidiegwu JE, Bryan GJ, Jones HG, Prashar A (2015) Coping with drought: stress and adaptive response in potato and perspective for improvement. Front Plant Sci 6:542. https://doi.org/10.3389/fpls.2015.00542

Prinzenberg AE, Víquez-Zamora M, Harbinson J, Lindhouta P, van Heusdena S (2018) Chlorophyll fluorescence imaging reveals genetic variation and loci for a photosynthetic trait in diploid potato. Physiol Plant 164:163-175

Rapacz M, Wójcik-Jagła M, Fiust A, Kalaji HM, Kościelniak J (2019) Genome-wide association of chlorophyll fluoresecence OJIP transient parameters connected with soil drought response in barley. Front Plant Sci 10:78

Raymundo R, Asseng S, Robertson R, Petsakos A, Hoogenboom G, Quiroz R, Hareau G, Wolf J (2018) Climate change impact on global potato production. Eur J Agron 100:87-98 
Rodríguez-Pérez L, Ñústez CE, Moreno LP (2017) Drought stress affects physiological parameters but not tuber yield in three Andean potato (Solanum tuberosum L.) cultivars. Agron Colomb 35(2):158-170

Roostaei M, Mohammadi SA, Amri A, Majidi E, Nachit M, Haghparast R (2011) Chlorophyll fluorescence parameters and drought tolerance in a mapping population of winter bread wheat in the highlands of Iran. Russ J Plant Physiol 58(2):351-358

Samborska IA, Kalaji MH, Sieczko L, Borucki W, Mazur R, Kouzmanova M, Goltsev V (2019) Can just onesecond measurement of chlorophyll a fluorescence be used to predict sulphur deficiency in radish (Raphanus sativus L. sativus) plants? Curr Plant Biol 19

Schafleitner R, Rosales ROG, Gaudin A, Aliaga CAA, Martinez GN, Marca LRT, Bolivar LA, Delgado FM, Simon R, Bonierbale M (2007) Capturing candidate drought tolerance traits in two native Andean potato clones by transcription profiling of field grown plants under water stress. Plant Physiol Biochem 45:673-690

Shi S, Fan M, Iwama K, Li F, Zhang Z, Jia L (2015) Physiological basis of drought tolerance in potato grown under long-term water deficient. Int J Plant Prod 9(2):305-320

Vertucci CW, Ellenson JL, Leopold AC (1985) Chlorophyll fluorescence characteristics associated with hydration level in pea cotyledons. Plant Physiol 79:248-252

Retuerto R, Fernández B, Obeso JR (2006) Changes in photochemical efficiency in response to herbivory and experimental defoliation in the dioecious tree Ilex aquifolium. Int J Plant Sci 167:279-289

Soltys-Kalina D, Plich J, Strzelczyk-Żyta D, Śliwka J, Marczewski W (2016) The effect of drought stress on the leaf relative water content and tuber yield of a half-sib family of 'Katahdin'-derived potato cultivars. Breed Sci 66:328-331

Strasser RJ, Srivastava A, Govindjee R (1995) Polyphasic chlorophyll a fluorescence transient in plants and cyanobacteria. Photochem Photobiol 61:32-42

Wang Y, Yang R, Zheng J, Shen Z, Xu X (2019) Exogenous foliar application of fulvic acid alleviate cadmium toxicity in lettuce (Lactuca sativa L.). Ecotox Environ Safe 167:10-19

Watkinson JI, Hendricks L, Sioson AA, Heath LS, Bohnert HJ, Grene R (2008) Tuber development phenotypes in adapted and acclimated, drought-stressed Solanum tuberosum ssp. andigena have distinct expression profiles of genes associated with carbon metabolism. Plant Physiol Biochem 46:34-45

Publisher's Note Springer Nature remains neutral with regard to jurisdictional claims in published maps and institutional affiliations.

\section{Affiliations}

\section{Jarosław Plich ${ }^{1}$ • Dominika Boguszewska-Mańkowska ${ }^{2}$. Waldemar Marczewski ${ }^{1}$}

Dominika Boguszewska-Mańkowska

d.boguszewska-mankowska@ihar.edu.pl

Waldemar Marczewski

w.marczewski@ihar.edu.pl

1 Plant Breeding and Acclimatization Institute-National Research Institute, Młochów Research Center, 19 Platanowa Str., 05-831 Młochów, Poland

2 Plant Breeding and Acclimatization Institute-National Research Institute, Jadwisin Research Center, 05140 Serock, Poland 